\title{
FIRST RECORD OF THE CUBERA SNAPPER, LUTJANUS CYANOPTERUS (ACTINOPTERYGII: PERCIFORMES: LUTJANIDAE), FROM THE AZORES (NE ATLANTIC) AND POSSIBLE RANGE EXTENSION FOR THE EAST ATLANTIC
}

\author{
Pedro A. RIBEIRO ${ }^{1,2}$, João M. GONÇALVES ${ }^{1,2}$, Govindraj CHAVAN ${ }^{1,2}$, Ronald FRICKE 3 , \\ Antonio M. GARCÍA-MEDEROS ${ }^{4}$, Víctor M. TUSET ${ }^{5}$, and João P. BARREIROS ${ }^{6 *}$ \\ ${ }^{1}$ Marine and Environmental Sciences Centre (MARE) and Institute of Marine Research IMAR, Horta, Portugal \\ ${ }^{2}$ Okeanos, R\&D Centre, University of the Azores, Horta, Portugal \\ ${ }^{3}$ Im Ramstal 76, 97922 Lauda-Königshofen, Germany \\ ${ }^{4}$ Grupo en Biodiversidad y Conservación, Instituto Ecoaqua, Parque Científico Tecnologico de Taliate, Telde, Spain \\ ${ }^{5}$ Institute of Marine Science (ICM-CSIC), Barcelona, Catalonia, Spain \\ ${ }^{6}$ Centre for Ecology, Evolution and Environmental Changes/Azorean Biodiversity Group (CE3C/ABG), Faculty of \\ Agrarian and Environmental Sciences, University of the Azores, Angra do Heroísmo, Portugal
}

Ribeiro P.A., Gonçalves J.M., Chavan G., Fricke R., García-Mederos A.M., Tuset V.M., Barreiros J.P. 2017. First record of the cubera snapper, Lutjanus cyanopterus (Actinopterygii: Perciformes: Lutjanidae), from the Azores (NE Atlantic) and possible range extension for the east Atlantic. Acta Ichthyol. Piscat. 47 (3): 259-263.

Background. A lutjanid recently captured in Flores Island represents the first documented record of a snapper for the Azores Islands. Since this specimen was not made available to us besides photographs and a muscle sample, a genetic study approach was necessary in order to accurately describe and discuss this somewhat unexpected occurrence. The main objective of this paper was to explain and discuss the presence of this single specimen in this part of the north-eastern Atlantic.

Materials and methods. The specimen was caught by spear fishers on 30 July 2014 off Flores Island. We analysed all available photographs and a sample of muscle tissue that was taken and preserved frozen to be used for DNA barcoding.

Results. The specimen was a reproductively mature female with a total length of $108.7 \mathrm{~cm}$ and weighing 14.84 $\mathrm{kg}$. The body depth of the specimen from the Azores was 2.9 in SL and the analyses conducted showed no divergence from the Canary Islands specimen reported by García-Mederos and Tuset (2014) as Lutjanus dentatus (Duméril, 1861) with the body depth of 2.5 in SL, which demonstrates that this character is highly variable and not useful for species identification.

Conclusions. The snapper specimen from the Island of Flores is a Lutjanus cyanopterus (Cuvier, 1828) and confirmed as first record for this part of the north-eastern Atlantic. Comparisons with a L. dentatus from the Canary Islands point towards synonymy although the available molecular evidence is too scarce and by no means conclusive.

Keywords: new record, species distribution, DNA barcoding, Macaronesia

\section{INTRODUCTION}

The snapper family Lutjanidae comprises a total of 17 genera (Nelson 2006) and approximately 110 species inhabiting tropical and subtropical coastal waters worldwide (Eschmeyer and Fong 2017, Froese and Pauly 2017). At least 17 species of the genus Lutjanus are known to occur in the Atlantic. There has been so far no evidence of amphi-Atlantic distribution for any of these, with 12 species recorded in the western Atlantic between Nova Scotia and south-eastern Brazil (Moura and Lindeman 2007), and five off the tropical and subtropical eastern Atlantic coast (Allen 1985). Among these, rare occurrences of the Gorean snapper, Lutjanus goreensis (Valenciennes, 1830) (see González and Santana 1986, Brito et al. 2005) and the African brown snapper, Lutjanus dentatus (Duméril, 1861) (see García-Mederos and Tuset 
2014), in the Canary Islands, and L. goreensis in Madeira (Wirtz et al. 2008) have been reported, but no Lutjanus species was previously known from the Azores. Here we report the first record of a lutjanid snapper in the Azores archipelago, extending the previously known geographical distribution of this family to the North-eastern Atlantic.

\section{MATERIAL AND METHODS}

The specimen was caught by spear fishers on 30 July 2014 off the coast of Fajã Grande, Flores Island, Azores $\left(39^{\circ} 27^{\prime} \mathrm{N}, 31^{\circ} 16^{\prime} \mathrm{W}\right)$, at around $10 \mathrm{~m}$ depth (Fig. 1). Morphological identification was based on photographs and using the key for Lutjanidae provided by FAO (Allen 1985). A sample of muscle tissue was taken and preserved frozen to be used for DNA barcoding.

A sample was also obtained from a specimen originally identified as Lutjanus dentatus (Fig. 2) that was recently caught in the Canary Islands (García-Mederos and Tuset 2014) to investigate if both specimens belonged to the same or different species.

Genomic DNA was extracted using the Jetquick Tissue DNA Spin Kit (Genomed) following the manufacturer's protocol. A fragment of the mitochondrial cytochrome $\mathrm{c}$ oxidase I gene (COI) was PCR amplified using primers FishF1 and FishR1 and protocols published by Ward et al. (2005). PCR products were purified using the PureLink PCR Purification Kit(Invitrogen), then forward and reverse- sequenced on an ABI 3730xl platform at Beckman Coulter Genomics (UK). Forward and reverse sequences were edited, assembled and trimmed to a final length of $677 \mathrm{bp}$ using CodonCode Aligner 6.0.2 (CodonCode Corporation, Centerville, MA, USA). Consensus sequences of the two specimens were queried against the Barcode of Life Data System database (BOLD) (Ratnasingham and Hebert 2007) in order to obtain a species-level identification based on high sequence similarity. A neighbor-joining phenogram based on the Kimura 2-parameter distance model was produced using the tree-based identification tool in BOLD, to provide a graphical representation of the placement of COI sequences in relation to reference sequences of Lutjanidae.

\section{RESULTS AND DISCUSSION}

The fish specimen from the Azores was a female presenting mature oocytes with a total length of 108.7 $\mathrm{cm}$ and weighing $14.84 \mathrm{~kg}$. Since we did not examine this specimen ourselves the description of the oocytes is from the catchers themselves. Although they obviously mentioned the presence of mature oocytes it is very risky to state in what precise stage they were. We have no photos of the oocytes although the most probable is that they were vitellogenic. From the examination of morphological characters according to Allen (1985), the specimen fitted the description of two species inhabit

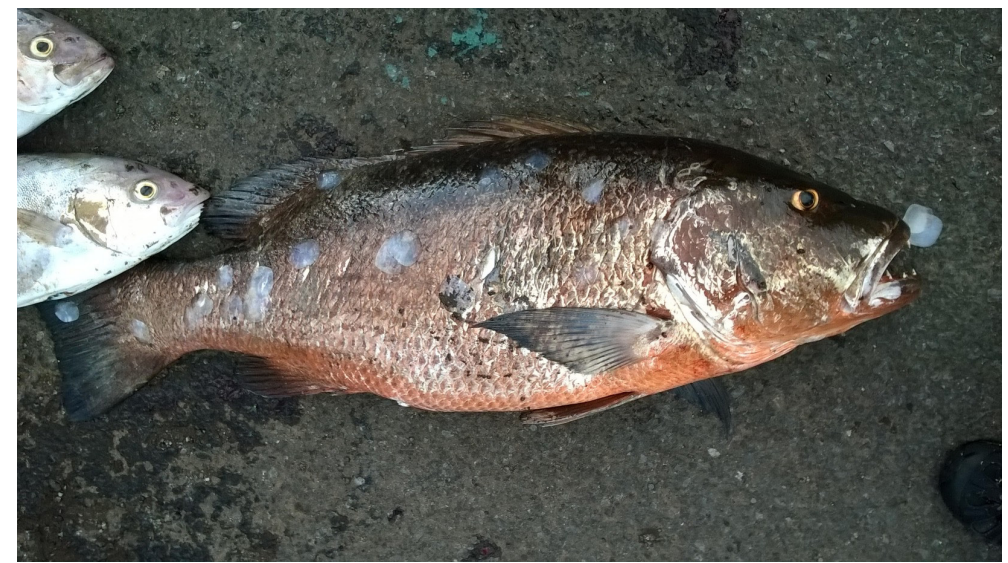

Fig. 1. The specimen of Lutjanus cyanopterus caught off Flores Island West coast, Azores (NE Atlantic); photo by Sílvio Gonçalves

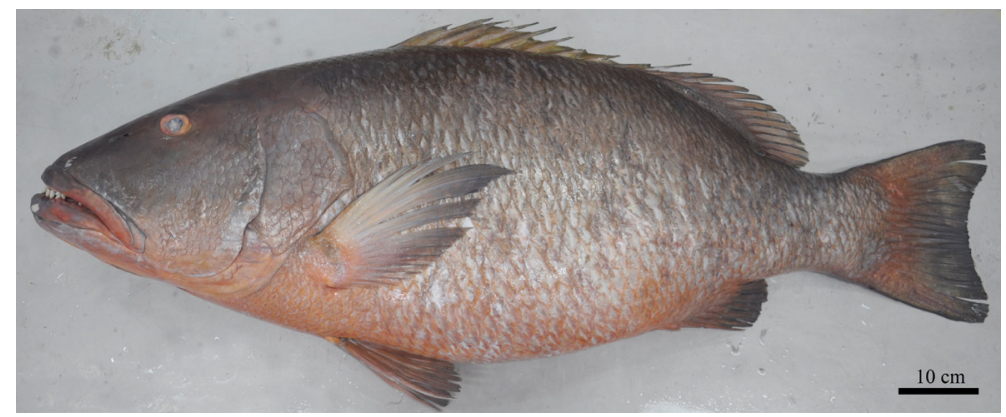

Fig. 2. Non-native specimen of Lutjanus dentatus collected in the Canary Islands and discussed in García-Mederos and Tuset (2014); photo by Antonio García-Mederos 
opposite margins of the Atlantic - the cubera snapper, Lutjanus cyanopterus (Cuvier, 1828), and the African brown snapper L. dentatus. Cubera snapper is known to occur along the east coast of America from Nova Scotia and Bermuda to south-eastern Brazil, including Florida, the West Indies, the Gulf of Mexico, the and Caribbean Sea (Moura and Lindeman 2007). African brown snapper has been reported on the eastern African coast between Senegal and Angola, including the Gulf of Guinea (Allen 1985), and recently in the Canary Islands (García-Mederos and Tuset 2014). In his identification keys, Allen (1985: pp. 47-49) did not compare the two species, as they were keyed out in separate keys for the western and eastern Atlantic, respectively. In the species descriptions (Allen 1985: p. 72 for L. cyanopterus, p. 74 for L. dentatus), both species are described with some intraspecific variation and overlap in the majority of their characters, some apparently also due to limited study material, without trenchant differences. Lutjanus cyanopterus is said to have the body relatively elongate and slender, and the caudal fin nearly truncate, while $L$. dentatus has a relatively deep body, and an emarginate caudal fin. In the illustrations, L. cyanopterus has the body depth 3.6 in SL, while L. dentatus has 3.2 in SL. This difference is most probably due to allometric growth, as the examined specimen of $L$. dentatus was much smaller than the L. cyanopterus. In fact, demographic variations within the same species could be an alternative explanation while we certainly would need age data to assess and compare ages, although there would still be some inherent variations for common ages. The specimen from the Azores had a proportion body depth 2.9 in SL, and the Canary Islands specimen, reported by García-Mederos and Tuset (2014), had 2.5 in SL, which demonstrates that this character is highly variable and not useful for species identification. The caudal fin shape was very similar in the specimens of the two species illustrated by Allen (1985), and judging from the illustrations the Azores specimen could be identified as either of the two. Other characters like the fin-ray counts, the lateral scale arrangement and the dentition are shared by the two nominal species.

The COI sequences obtained for the specimen here described and the L. dentatus individual reported by GarcíaMederos and Tuset (2014) were identical. Moreover, there was a $99.69 \%-99.84 \%$ match to $L$. cyanopterus reference sequences available in the BOLD database. This very low level of divergence is considered to support a reliable identification, except if a very closely related congener has been excluded from the analysis. Given that four of the eastern Atlantic Lutjanus species do not have publicly available barcodes, and were thus not included in this study, such possibility cannot be entirely ruled out. This seems, however, very unlikely for two reasons. First, all eastern Atlantic species are morphologically well differentiated, and therefore the chances of misidentification are minimal. Second, within genus Lutjanus, the range of COI sequence divergence was much lower at the intraspecific than at interspecific level (Fig. 3, supporting information). A similar pattern had already been uncovered for western
Atlantic Lutjanus by Victor et al. (2009), who found high levels of divergence between species $(2.7 \%-11.4 \%)$ but very low differentiation within species $(<0.5 \%)$.

Given the morphological similarity and the proven reliability of DNA barcoding in the identification of lutjanid snappers, no trenchant differences were found between L. cyanopterus and $L$. dentatus, suggesting that the two nominal species may represent a single biological species with amphi-Atlantic distribution. In that case, the name Lutjanus cyanopterus (Cuvier, 1828) would have priority over Lutjanus dentatus (Duméril, 1861). Another possible cause is that the specimen described in García-Mederos and Tuset (2014) was wrongly identified. Contrasting with their western counterparts (e.g., Victor et al. 2009, Gold et al. 2011), there have been to date no molecular studies focusing on eastern Atlantic snappers. Therefore, not only their taxonomic status needs to be verified using molecular and morphological methods, but also very little can be said about the evolutionary relations between eastern and western Atlantic species. This is a subject deserving further investigation under a phylogenetic framework based on a set of both mitochondrial and nuclear markers.

In light of the presently reported results, it is difficult to identify the origin of the individual caught in Flores, as in theory there are two possible dispersal pathways. Given that adults are restricted to shallow-water benthic habitats, dispersal from the natal area took place most likely during the pelagic larval stage. A pelagic larval duration (PLD) of around 29 days has been estimated for L. cyanopterus based on larval otolith analysis (Victor et al. 2009). Some variation in PLD estimates was reported for other lutjanid species, which may be related to water temperature and habitat availability (Zapata and Herrón 2002, Denit and Sponaugle 2004). Assuming that cubera snapper larvae take longer to develop at lower temperatures and are able to delay settlement until suitable habitat is reached, larvae transported eastwards from the American coast during a period of strong Gulf Stream and Azores Current flows may have just had enough time to reach the Azores and settle. In line with this hypothesis is the fact that this individual was found on the westernmost stretch of coast in the archipelago, although it is difficult to draw any conclusions based on just one observation. In fact, the DNA seems to indicate that these two specimens do represent $L$. cyanopterus and that the L. dentatus specimen was originally misidentified. Whether these are one-off transports of larvae from the western Atlantic or that they represent a localized population is still unclear, however the fact that the Azores sample was gravid may suggest the latter.

On the other hand, it is also possible that dispersal occurred from West Africa or the Canaries, either by a single long-distance transport event or through steppingstone dispersal via the Canaries and Madeira over the course of several generations. The second scenario seems less likely, since there have been no records of $L$. dentatus in Madeira and no evidence of an established population in the Canaries. While surface circulation patterns can hardly explain westward larval transport over such a 


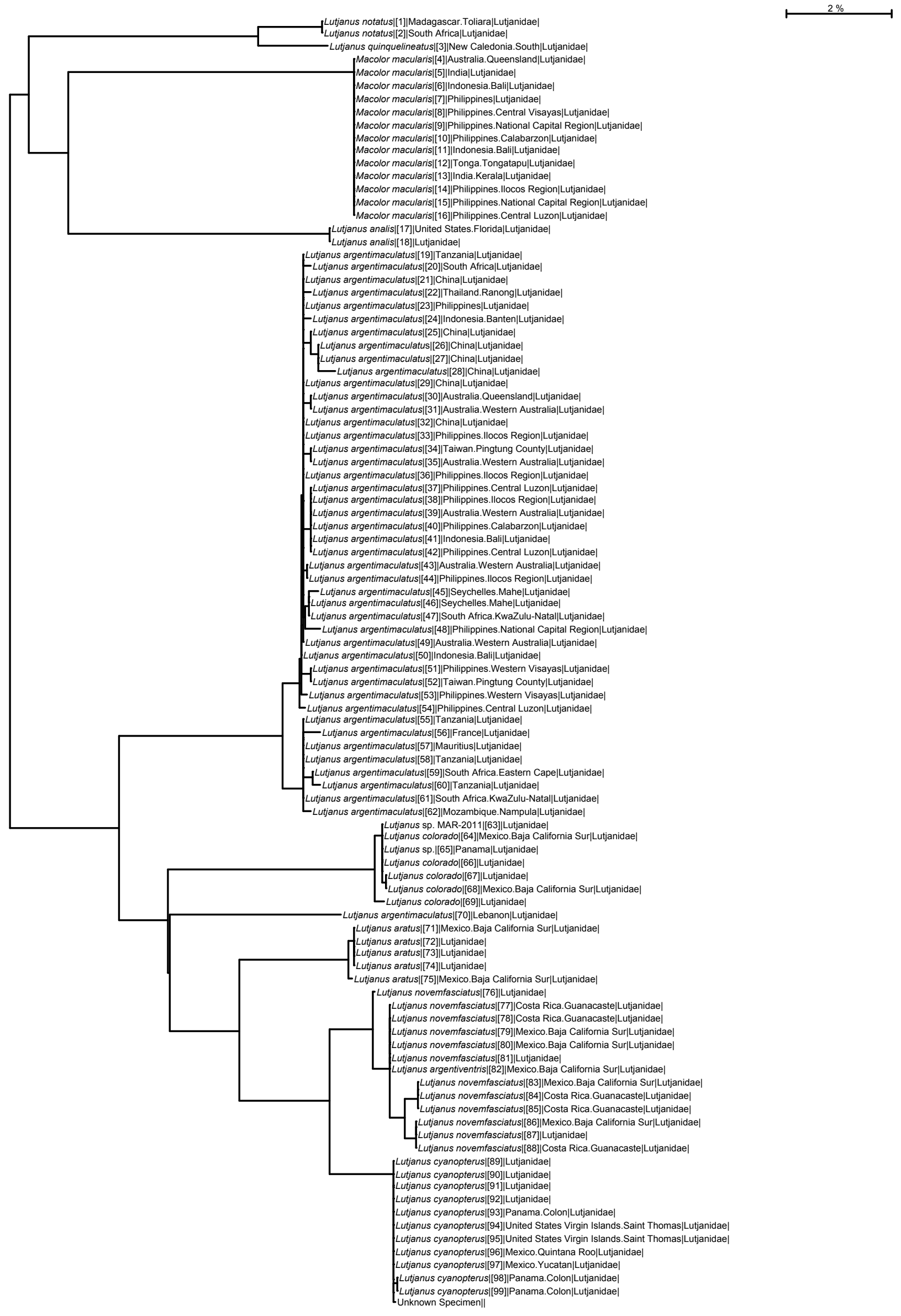

Fig. 3. BOLD neighbor-joining tree based on K2P distances of public COI DNA barcodes from Lutjanidae; unknown specimen refers to the haplotype obtained for both specimens sequenced in this study 
long distance, the complete identity of COI sequences from the Azores and the Canaries, together with a slight divergence from western Atlantic ones, suggests that the source population may be located in the east Atlantic. The available molecular evidence is, however, too scarce and by no means conclusive. A comparison of genetic variation between populations from both sides of the Atlantic using high-resolution markers would help clarify this issue.

\section{ACKNOWLEDGMENTS}

We are grateful to Pedro Lima and Sílvio Gonçalves who collected the specimen and kindly gave us all information possible as well as several photos. PAR was supported by an FCT post-doctoral grant (ref. SFRH/BPD/69232/2010). GC was supported by an FRCT Doctoral Grant (ref. M3.1.2/F/056/2011).

\section{REFERENCES}

Allen G.R. 1985. FAO species catalogue. Vol. 6. Snappers of the world. An annotated and illustrated catalogue of lutjanid species known to date. FAO Fisheries Synopsis No. 125.

Brito A., Falcón J.M., Herrera R. 2005. Sobre la tropicalización reciente de la ictiofauna litoral de las islas Canarias y su relación con cambios ambientales y actividades antrópicas. Vieraea 33: 515-525.

Denit K., Sponaugle S. 2004. Growth variation, settlement, and spawning of gray snapper across a latitudinal gradient. Transactions of the American Fisheries Society 133 (6): 1339-1355.

DOI: $10.1577 / \mathrm{T} 03-156.1$

Eschmeyer W.N., Fong J.D. 2017. Catalog of fishes: Species by family/subfamily. http://researcharchive. calacademy.org/research/ichthyology/catalog/ SpeciesByFamily.asp [Accessed on 04 April 2017.]

Froese R., Pauly D. (eds.) 2017. FishBase. [Version 02/2017] www.fishbase.org
García-Mederos A.M., Tuset V.M. 2014. First record of African brown snapper Lutjanus dentatus in the Canary Islands (north-eastern Atlantic Ocean). Marine Biodiversity Records 7: e65.

DOI: $10.1017 / \mathrm{S} 1755267214000682$

Gold J.R., Voelker G., Renshaw M.A. 2011. Phylogenetic relationships of tropical western Atlantic snappers in subfamily Lutjaninae (Lutjanidae: Perciformes) inferred from mitochondrial DNA sequences. Biological Journal of the Linnean Society 102 (4): 915-929. DOI: $10.1111 /$ j.1095-8312.2011.01621.x

González J.A., Santana J.I. 1986. Sobre la presencia de Lutjanus goreensis (Valenciennes, 1830) (Osteichthyes: Lutjanidae) en aguas de Canarias. Vieraea 16: 282-286.

Moura R.L., Lindeman K.C. 2007. A new species of snapper (Perciformes: Lutjanidae) from Brazil, with comments on the distribution of Lutjanus griseus and L. apodus. Zootaxa 1422: 31-43.

Nelson J.S. 2006. Fishes of the world. 4th edn. John Wiley and Sons, Hoboken, NJ, USA.

Ratnasingham S., Hebert P.D.N. 2007. BOLD: The Barcode of Life Data System (www.barcodinglife. org). Molecular Ecology Notes 7 (3): 355-364.

DOI: $10.1111 /$ j.1471-8286.2007.01678.x

Victor B.C., Hanner R., Shivji M., Hyde J., Caldow C. 2009. Identification of the larval and juvenile stages of the cubera snapper, Lutjanus cyanopterus, using DNA barcoding. Zootaxa 2215: 24-36.

Wirtz P., Fricke R., Biscoito M.J. 2008. The coastal fishes of Madeira Island-new records and an annotated check-list. Zootaxa 1715: 1-26.

Zapata F.A., Herrón P.A. 2002. Pelagic larval duration and geographic distribution of tropical eastern Pacific snappers (Pisces: Lutjanidae). Marine Ecology Progress Series 230: 295-300. DOI: $10.3354 /$ meps 230295

Received: 21 April 2017

Accepted: 17 July 2017 Published electronically: 30 September 2017 